\title{
Determinants of health related quality of life in a sample of patients with chronic obstructive pulmonary disease in Nigeria using the St. George's respiratory questionnaire
}

\author{
*Obaseki DO ${ }^{1}$ Erhabor GE ${ }^{1}$ Awopeju $\mathrm{OF}^{1}$ Obaseki $\mathrm{JE}^{2}$ Adewole OO${ }^{1}$
}

1. Department of Medicine, Obafemi Awolowo University, Ile-Ife, Nigeria.

2. Department of Preventive and Community Dentistry, Obafemi Awolowo University Teaching Hospital, Ile-Ife, Nigeria

\begin{abstract}
Background: Chronic Obstructive Pulmonary Disease (COPD) is a multi-systemic and progressive disease. However the determinants of its impact on health related quality of life are not well-studied or understood in Nigeria.

Objectives: 'To assess the determinants of health related quality of life in COPD

Methods: Patients with stable COPD were recruited consecutively from the outpatient clinics of a university hospital. Health Related Quality of Life (HRQL) was assessed using the St. George's Respiratory Questionnaire (SGRQ) and the Forced Expiratory Volume in one second (FEV1), Forced Vital Capacity (FVC) were measured by a vitalograph spirometer. Results: Fifty patients were recruited for this study (male $=60 \%)$. The mean $(\mathrm{SD})$ age was $69(9)$ years. The overall mean $(\mathrm{SD})$ SGRQ scores was 45.9 (26.5), 50.6 (29.2), 29.7 (19.9), 38.8 (22.0) for the symptom, activity, impact and total scores respectively. After adjusting for age, sex and smoking, self-reported breathlessness independently predicted on average 25.2, 36.8, 13.65 and 22.9 points increase in SGRQ symptom, activity, impact and total scores respectively. Self-reported weight loss predicted 12.2 points increase in the impact subscale.

Conclusions: Self-reported breathlessness and weight loss are independent predictors of low HRQL score in COPD.

Key words: Chronic obstructive pulmonary disease, Health related quality of life, St George’s Respiratory Questionnaire, Nigeria.

African Health Sciences 2013; 13(3): 694 - 702 http://dx.doi.org/10.4314/ahs.v13i3.25
\end{abstract}

\section{Introduction}

Chronic Obstructive Pulmonary Disease (COPD) is a growing cause of morbidity and mortality. It is projected to become the third leading cause of death worldwide by $2030^{1,2}$. Although significant progress has been made in the assessment and management of patients with COPD over the last four decades, the care of persons with this disease remains challenging because of it's progressive and multisystemic nature.

COPD is usually assessed using outcome measures like number of hospitalization, exacerbations, mortality and lung function parameters ${ }^{3,4}$. However these measures do not provide a comprehensive assessment of the health status of the patients. There is growing evidence that shows that relying only on mortality and lung function

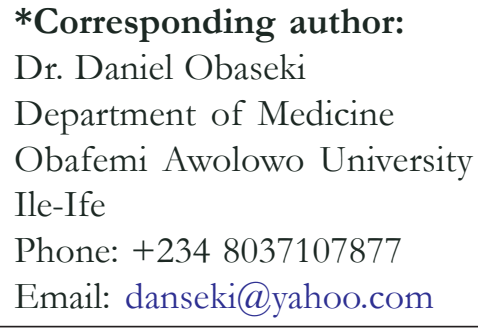

measures for assessing effectiveness of treatments could be misleading in conditions like COPD that have notable non-respiratory systemic manifestations ${ }^{5,6}$. As such, Health Related Quality of Life (HRQL) measures have achieve widespread acceptance because they provide a holistic assessment of the impact of the disease and benefits of treatments. Among these quality of life measures, the St Georges Respiratory Questionnaire (SGRQ) has been shown to be valid and specific for $\mathrm{COPD}^{7}$, ${ }^{8}$.

Quality of life (QoL) evaluation is relatively new in developing countries. It can influenced by various factors including socio-economic status and may vary between populations ${ }^{9,10}$. We are unaware of any study in Nigeria that has assessed the quality of life of patients with COPD. The relation of QoL measures to traditional outcomes of COPD like lung function measures and the factors that predict them are not well understood.

The use of quality of life instruments holds potential use in rural and suburban health facilities in developing countries where access to spirometry and other objective measures of lung function may be 
lacking. The availability of adapted QoL measures may provide substantial and complementary benefit for patients with COPD and their care providers. The aim of this study was to assess the relation of SGRQ scores to lung function especially forced expiratory volume in one second (FEV1), forced vital capacity (FVC) and to determine the factors that predict its component and total scores.

\section{Methods}

\section{Study design}

It was a cross-sectional study carried out at the medical outpatient department of Obafemi Awolowo University Teaching Hospital (OAUTH), Ile-Ife. OAUTH is a tertiary hospital located in southwest Nigeria.

\section{Study participants}

Fifty (50) patients with stable COPD according to the Global Initiative for Chronic Obstructive Lung Disease (GOLD) criteria were recruited consecutively from the outpatient clinics of Obafemi Awolowo University Teaching Hospital (OAUTH), Ile-Ife ${ }^{11}$.

The inclusion criteria comprised of patients with:

1. chronic airflow impairment - percentage of forced expiratory volume in one second less than $80 \%$ predicted and ratio of forced expiratory volume in one second to forced vital capacity $\left(\mathrm{FEV}_{1} / \mathrm{FVC}\right)$ less than 0.7 ,

2. a bronchodilator reversibility test with change in $\mathrm{FEV}_{1}$ less than $15 \%$ and/or $200 \mathrm{ml} 20$ minutes after inhalation of 400 micrograms of Salbutamol,

3. clinically stable as defined by no change in medication dosage, frequency and no exacerbation or hospital admissions in the preceding six weeks.

Those excluded were; persons with a history of asthma, atopy or nasal polyps, patients who demonstrated a remarkable response and reversibility to Salbutamol as noted by FEV1 change above 15\% and/or $200 \mathrm{ml}$, patients with active lung disease like Tuberculosis or Bronchiectasis and those with comorbid conditions that could contribute to dyspnoea or exercise limitation like hypertensive heart failure

\section{Measurements}

\section{Health Status Measurement}

HRQL was assessed using the SGRQ ${ }^{8}$. The SGRQ has been used extensively for assessing QoL in patients with COPD and several other chronic lung diseases ${ }^{12-}$ ${ }^{14}$. It was developed by PW Jones of the St George's hospital medical school, London in 1991. It is sensitive, valid, reliable and responsive among patients with COPD. It contains 50 items with 76 weighted responses that cover three domains: symptoms - distress due to respiratory symptoms, activity - disturbances of physical activity and impact - overall impact on daily life and well-being. In addition to the domain scores, there is also a total score $^{7}$. The SGRQ is scaled from zero to 100 (with zero representing the best health-related quality of life). This questionnaire which was forward and back translated in Yoruba language, was administered to each participant. However those unable to selfcomplete the questionnaire due to shaky hands, inability to read, or poor eye sight had the questionnaire read to them in the exact format in which they were set out without bias or undue emphasis and their responses were ticked as appropriate.

\section{Lung function parameters}

Lung function test was performed using a standardized vitalograph bellows spirometer (Vitalograph Ltd, Buckingham, England). The following parameters were measured: forced expiratory volume in one second $\left(\mathrm{FEV}_{-}\right)$and forced vital capacity (FVC). The reference values

were derived using equations from a study by FemiPearse et $\mathrm{al}{ }^{15}$. The parameters were assessed before and 20 minutes after the inhalation of 400ig of Salbutamol using a metered dose inhaler (MDI) and a spacer device. The spacer was attached to the MDI and held in the mouth. After the patient had exhaled to functional residual capacity (FRC), the canister was activated. The patient inhaled slowly to total lung capacity (TLC) and held his/her breathe for ten (10) seconds ${ }^{16}$. This was done twice for every $200 \mu \mathrm{g}$ of Salbutamol released into the spacer device.

\section{Exercise testing and dyspnoea rating}

Exercise performance was evaluated using the six minutes walk test (6-MWT) according to the American Thoracic Society guideline ${ }^{17}$. It is a simple, easy to administer and well tolerated functional walking test which is representative of the activities of daily living (ADL). This test was performed on a long, flat, straight and enclosed corridor. The walking course was $30 \mathrm{~m}$ (100 -feet). The length of the corridor was marked every $3 \mathrm{~m}$ and the turnaround points were also noted. A starting line, which marks the beginning and end of $60 \mathrm{~m}$ lap, was marked on the floor using a brightly coloured marker. Patients appeared in their normal clothing on the day of the test with their shoes and walking aid, if any. The 
length walked was measured and the level of perceived breathlessness was measured both before and after the walk test using the visual analogue scale (VAS)

The VAS is a dynamic scale used to assess a patient's perceived breathlessness. It has been shown to be a valid measure of dyspnoea on exertion ${ }^{18}$. The visual analogue scale consisted of a $20 \mathrm{~cm}$ horizontal line. The word 'No Breathlessness' was written at the left end of the scale, 'Very Severe Breathlessness' was at the right end of the scale. It was scored from 0 to 100. Ratings were expressed as percents of the full VAS line length. Participants were asked to grade their shortness of breath with the scale before and after the six minutes walk test.

\section{Data collection and Analysis}

A proforma was used in recording sociodemographic data from each patient. Mean values and standard deviation (SD) was computed for all continuous parameters and frequencies and proportions for categorical variables. The correlation between quality of life scores, dyspnoea rating, six minutes walking distance and physiological parameters was assessed using Pearson's linear correlation coefficient.

The St Georges respiratory questionnaire was statistically analyzed using the excel-based scoring calculator from the developer. To identify the factors that influenced HRQL in these patients, a linear regression analysis was used. The model with the best fit was assessed using the changes in the Rsquared values adjusting for age, sex and smoking pack years. Ethical clearance was obtained from the hospital ethics committee and verbal informed consents were obtained from participants included in the study.

\section{Results}

Fifty patients were recruited for this study and sixty percent of the respondents were male. The mean age and standard deviation was 69 (9) years, body mass index (BMI) 22(5). The proportion of the stages of COPD were $10 \%, 34 \%, 34 \%$ and $22 \%$ for mild, moderate, severe and very severe stages of the disease respectively. The mean pre-bronchodilator FEV1 and FVC were $801 \mathrm{ml}$ and $1520 \mathrm{ml}$ while the post bronchodilator FEV1 and FVC were $817 \mathrm{ml}$ and $1570 \mathrm{ml}$ respectively. The overall mean (SD) SGRQ scores were 45.9 $\pm 26.5,50.6 \pm 29.2,29.7 \pm$ $19.9,38.8 \pm 22.0$ for the symptom, activity, impact and total scales respectively (table 1$)$.
Table 1: General characteristics of the participants $(n=50)$

\begin{tabular}{lc}
\hline Variable & Mean \pm SD or $\mathbf{n ~ ( \% ) ~}$ \\
\hline Age (years) & $69 \pm 9$ \\
Height $(\mathrm{cm})$ & $162 \pm 9$ \\
BMI $\left(\mathrm{Kg} / \mathrm{m}^{2}\right)$ & $22 \pm 5$ \\
FEV1-pre $(\mathrm{ml})$ & $801 \pm 439$ \\
FEV1-post $(\mathrm{ml})$ & $818 \pm 405$ \\
FVC-pre $(\mathrm{ml})$ & $1520 \pm 679$ \\
FVC-post $(\mathrm{ml})$ & $1570 \pm 655$ \\
FEV1/FVC $(\%)$ & $51 \pm 12$ \\
6 MWD (m) & $361 \pm 85$ \\
VAS-dyspnea before 6MWD $(\%)$ & $10 \pm 15$ \\
VAS-dyspnea after 6MWD (\%) & $29 \pm 22$ \\
SGRQ score & \\
Symptom & $45.9 \pm 26.5$ \\
Activity & $50.6 \pm 29.2$ \\
Impact & $29.7 \pm 19.9$ \\
Total & $38.8 \pm 22.0$ \\
Sex (male) & $30(60)$ \\
*GOLD Classification of COPD \\
Mild & $5(10)$ \\
Moderate & $17(34)$ \\
Severe & $17(34)$ \\
Very Severe & $11(22)$ \\
Occupation & \\
Artisans & $8(16)$ \\
Farmers & $17(34)$ \\
Professionals & $5(10)$ \\
Teachers & $5(10)$ \\
Traders & $15(30)$ \\
\hline FEl Fon &
\end{tabular}

FEV1 - Forced expiratory volume in one second, FVC- Forced vital capacity, pre- prebronchodilator, post-bronchodilator, VAS- visual analogue scale, SGRQ- St George's Respiratory Questionnaire, BMI- Body Mass Index; 6 MWD-6 Minutes Walking Distance. GOLD- Global initiative for Chronic Obstructive Lung Disease;

*Post bronchodilator FEV1/FVC $<70 \%$. FEV1 > $80 \%$ predicted (Mild) $50 \%<=$ FEV1 $<80 \%$ predicted (Moderate); 30\% < =FEV1 < 50\% predicted (Severe); FEV1 $<30 \%$ predicted (Very severe).

Men had mean (SD) SGRQ scores of 42.1 (27.8), 47.5 (30.8), 27.2 (20.3), 36.0 (22.9) and for women the scores were 51.6 (23.9), 55.2 (26.7), 33.4 (19.2), 43.0 (20.4) in the symptom, activity, impact and total scales respectively. Women had worse SGRQ scores compared with men. As expected, previous heavy smokers had worse SGRQ score in the symptom subscale compared to never smokers (Data not shown). There was no current smoker in the sample. 
Table 2 shows the correlation coefficients between the SGRQ scores, lung function parameters, six minutes walking distance and VAS dyspnoea scores. The coefficients for FEV1 pre-bronchodilator were $-0.19,-0.36,-0.26$ and -0.31 for SGRQ symptoms, activity, impact and total scores respectively. The coefficients for pre- bronchodilator FVC were $-0.13,-0.32,-0.18$ and -0.24 respectively. The coefficients for pre-bronchodilator FEV1 and FVC were higher than the post bronchodilator values. The VAS scores post exercise showed correlation coefficients of 0.16, 0.36, 0.41 and 0.38 for SGRQ symptoms, activity, impact and total scores respectively. The activity subscale and total score demonstrated the best SGRQ correlation to FEV1, albeit weak, to lung function variables.

Table 3 shows the results of the univariate analysis of the various study parameters. Notably, the self reported dyspnoea and weight loss were important predictors for the SGRQ total and sub scores. Those reporting dyspnoea on average had 27.82, 29.46, 10.70 and 19.48 points higher scores (indicating worse quality of life) in the total, symptoms, activity and impact scales respectively.

Table 4 presents the result of the multivariate analysis adjusting for age, sex, smoking and FEV1. It shows that self reported breathlessness independently predicts on average 25.2, 36.8, 13.65 and 22.9 points increase in SGRQ symptom, activity, impact and total scores respectively. Adjusting for age, sex, pack years of smoking, reported symptoms like weight loss, breathlessness, VAS score post exercise and lung function, the model accounted for $24 \%, 42 \%, 27 \%$ and $35 \%$ of the variance in the SGRQ symptom, activity, impact and total score respectively.

Table 2: Pearson correlation coefficient of SGRQ scores

\begin{tabular}{lllll}
\hline & Symptom & Activity & Impact & Total \\
\hline FEV1- Pre & -0.19 & $\mathbf{- 0 . 3 6 *}$ & -0.26 & $\mathbf{- 0 . 3 1 *}$ \\
FEV1-Post & -0.13 & $\mathbf{- 0 . 3 2 *}$ & -0.21 & -0.26 \\
FVC-Pre & -0.13 & $\mathbf{- 0 . 3 2 *}$ & -0.18 & -0.24 \\
FVC-Post & -0.07 & -0.24 & -0.14 & -0.18 \\
FEV1/FVC & -0.07 & -0.25 & -0.14 & -0.18 \\
6 MWD & -0.21 & -0.24 & $\mathbf{- 0 . 3 2 *}$ & $\mathbf{- 0 . 3 0 *}$ \\
VAS -Post & 0.16 & $\mathbf{0 . 3 6 *}$ & $\mathbf{0 . 4 1 * *}$ & $\mathbf{0 . 3 8 * *}$ \\
exercise & & & & \\
\hline
\end{tabular}

$* p<0.05 \quad * * p<0.01$

FEV1 - Forced expiratory volume in one second, FVC- Forced vital capacity, PRE- prebronchodilator, POST-bronchodilator, VAS- visual analogue scale, SGRQ- St George's Respiratory Questionnaire, 6 MWD 6 Minutes Walking Distance, Significant values in bold

\section{Discussion}

The SGRQ designed by Jones PW has been used widely for measuring HRQL in persons with COPD especially in drug trials and other controlled interventional studies ${ }^{19,20}$. Recently, a shorter version derived from the SGRQ, which is described as COPD Assessment Test (CAT) was developed by the same author ${ }^{21}$. However the use and relevance of these assessment tools in patients in low-income countries where access to respiratory care, spirometry and other modalities of managing COPD are largely inaccessible, is not well studied or understood.

We found that patients with COPD had low selfperceived quality of life especially in the 'symptom' and 'activity' subscales of the SGRQ. HRQL showed a significant association with dyspnoea measures but showed weak and inverse relationship with spirometry. In addition, self reported dyspnoea and weight loss were the strongest independent predictors of HRQL.

The quality of life scores of the present study generally indicate the patients had poor health status. In healthy individuals without symptoms of respiratory diseases, SGRQ scores are usually less than 15 units ${ }^{22}$ and in clinical trials on patients with COPD, the minimum clinically important difference (MCID) for efficacy of a treatment is estimated to be 4 units $^{23,24}$. However, in cross sectional studies of diseased individuals, a relative approach is often used.in interpretation of SGRQ scores. Scores tending towards 100 are generally indicative of worse health status while scores tending towards 0 indicate a better quality of life score ${ }^{7}$. 
Table 3: Univariate regression analysis of SGRQ total and component scores on study parameters

\begin{tabular}{|c|c|c|c|c|}
\hline & Total & $\begin{array}{l}\text { Symp- } \\
\text { tom }\end{array}$ & Activity & Impact \\
\hline Age (years) & 0.16 & -0.12 & 0.33 & 0.18 \\
\hline Sex (Male) & -6.99 & -9.47 & -7.70 & -6.16 \\
\hline Height $(\mathrm{cm})$ & 0.03 & -0.24 & -0.06 & 0.15 \\
\hline $\mathrm{BMI}\left(\mathrm{Kg} / \mathrm{m}^{2}\right)$ & -0.14 & 0.32 & -0.06 & -0.32 \\
\hline Smoking status & -1.32 & -1.13 & -0.52 & -1.86 \\
\hline Smoking pack years & 0.07 & 0.44 & -0.23 & 0.08 \\
\hline $6 \mathrm{MWD}(\mathrm{m})$ & -0.08 & -0.07 & -0.08 & -0.08 \\
\hline FEV1-pre & -0.02 & -0.01 & -0.02 & -0.01 \\
\hline FEV1-post & -0.01 & -0.01 & -0.02 & -0.01 \\
\hline FVC-pre & -0.01 & -0.01 & -0.01 & -0.01 \\
\hline FVC-post & -0.01 & 0.00 & -0.01 & 0.00 \\
\hline FEV1/FVC & -0.35 & -0.16 & -0.63 & -0.24 \\
\hline VAS 1 & 0.31 & 0.38 & 0.30 & 0.28 \\
\hline VAS 2 & 0.38 & 0.19 & 0.48 & 0.37 \\
\hline Gold classication & 2.69 & 0.70 & 5.27 & 1.56 \\
\hline \multicolumn{5}{|c|}{ Self-reported symptoms } \\
\hline Cough & -7.16 & 4.10 & -36.03 & 5.65 \\
\hline Sputum & 16.87 & 23.42 & 17.11 & 14.60 \\
\hline Wheeze & 6.54 & 12.92 & 6.72 & 4.23 \\
\hline Dyspnea & 27.82 & 29.31 & 40.93 & 19.48 \\
\hline Weight loss & 16.38 & 15.86 & 17.26 & 15.53 \\
\hline Chest tightness & 6.43 & 13.46 & 10.70 & 1.51 \\
\hline Chest pain & 5.61 & 6.59 & 7.14 & 4.92 \\
\hline Occupation & 0.34 & 0.75 & 1.01 & -0.07 \\
\hline Cooking fuel* & -1.84 & -6.48 & -1.94 & -0.61 \\
\hline
\end{tabular}

GOLD - Global initiative for chronic Obstructive Lung Disease. VAS1 - Visual Analogue Score pre-exercise, VAS 2 - Visual Analogue Score post-exercise, BMI= Body Mass Index; FEV1 - Forced Expiratory Volume in one second, FVC- Forced Vital Capacity, pre- prebronchodilator, post-postbronchodilator, SGRQ- St George's Respiratory Questionnaire, BMI- Body Mass Index, 6 MWD -6 Minutes Walking Distance.

*Cooking fuel types included Firewood, Kerosene, Liquefied natural gas and Electric cooker Significant variables at $\mathrm{p}<0.05$, are in bold

We found weak correlation between HRQL and Spirometry. The activity and total scales of the SGRQ showed the best correlation with pre-bronchodilator FEV1, but the coefficients were generally low (Figure 1a-d). A similar observation was found between SGRQ total score and post bronchodilator lung function values (Figure 2). Various correlation coefficients have been reported between HRQL and spirometry by several authors but the coefficients are usually weak ${ }^{8,25}$. Spirometry objectively evaluates the lung's functional and ventilatory capacity however it often fails to evaluate the non-ventilatory manifestations of COPD like weight loss, mood changes including depression. Overall, it seems that spirometry and HRQL are important tools, which evaluate different aspects of the disease especially the impact on patients daily functioning. Spirometry evaluates the functional aspects of the airway calibre and informs on the progression of the disease, a measure described as a 'hard' measure by PW Jones $^{26}$. However HRQL provides a holistic evaluation of the total impact of the disease especially in manifestations other than airway obstruction like weight loss, mood swings which explains its description as a 'soft' measure ${ }^{26}$. The combination of quality of life measures to the functional measures obtained from spirometry may provide a more thorough and comprehensive evaluation of patients with COPD.

The notable predictors of HRQL were selfreported breathlessness, weight loss, wheeze, sputum production and patient's subjective perception of 
Table 4: Multivariate regression analvses of determinants of health related qualitv of life

\begin{tabular}{|c|c|c|c|c|c|c|}
\hline \multirow{2}{*}{ TOTAL SGRQ } & \multirow[t]{2}{*}{ Coefficient } & \multirow[t]{2}{*}{ SE } & \multicolumn{2}{|c|}{$95 \% \mathrm{Cl}$} & \multirow[t]{2}{*}{$p$ value } & \multirow[t]{2}{*}{ R squarec } \\
\hline & & & & & & \\
\hline Weight loss & 11.14 & 5.59 & -0.14 & 22.43 & 0.053 & \\
\hline FEV1_post & 0.00 & 0.01 & -0.01 & 0.02 & 0.782 & Adjusted \\
\hline Breathlessness & 22.91 & 6.20 & 10.41 & 35.41 & 0.001 & $\mathrm{R} 2=0.35$ \\
\hline VAS post exercise & 0.24 & 0.12 & -0.01 & 0.49 & 0.060 & \\
\hline \multicolumn{7}{|l|}{ SYMPTOM SGRQ } \\
\hline Weight loss & 5.17 & 7.65 & -10.26 & 20.61 & 0.502 & \multirow{4}{*}{$\begin{array}{l}\text { Adjusted } \\
\text { R2 }=0.27\end{array}$} \\
\hline FEV1_post & 0.00 & 0.01 & -0.02 & 0.02 & 0.845 & \\
\hline Breathlessness & 25.20 & 8.02 & 9.01 & 41.39 & 0.003 & \\
\hline Sputum & 18.30 & 11.94 & -5.79 & 42.40 & 0.133 & \\
\hline \multicolumn{7}{|l|}{ ACTIVITY SGRQ } \\
\hline Weight loss & 10.37 & 6.98 & -3.72 & 24.46 & 0.145 & \multirow{4}{*}{$\begin{array}{l}\text { Adjusted- } \\
\text { R2=0.42 }\end{array}$} \\
\hline Breathlessness & 36.81 & 7.74 & 21.20 & 52.42 & 0.000 & \\
\hline VAS post exercise & 0.26 & 0.15 & -0.05 & 0.57 & 0.099 & \\
\hline FEV1_post & 0.00 & 0.01 & -0.02 & 0.02 & 0.689 & \\
\hline \multicolumn{7}{|l|}{ IMPACT SGRQ } \\
\hline Weight loss & 12.20 & 5.35 & 1.40 & 22.99 & 0.028 & \multirow{4}{*}{$\begin{array}{l}\text { Adjusted- } \\
\text { R2=0.24 }\end{array}$} \\
\hline FEV1_post & 0.00 & 0.01 & -0.01 & 0.02 & 0.532 & \\
\hline Breathlessness & 13.65 & 5.93 & 1.69 & 25.61 & 0.026 & \\
\hline VAS post exercise & 0.28 & 0.12 & 0.04 & 0.51 & 0.023 & \\
\hline
\end{tabular}

CI- Confidence Interval; FEV1- Forced Expiratory Volume in one second; VAS- Visual Analogue Scale; SGRQ - St George's Respiratory Questionnaire; SE- Standard Error; Post - postbronchodilator The model adjusted for age, sex and smoking with SGRQ 'total' 'symptom' 'activity' and 'Impact' scores as dependent variables Significant variables at $\mathrm{p}<0.05$, are in bold

breathlessness measured on the visual analogue scale post exercise. Age, body mass index, social class and GOLD staging of the disease did not significantly influence or predict HRQL. However, in the multivariate model, the key predictor of HRQL was self reported breathlessness. This observation shows that breathlessness during exercise or performance of daily activity is an important determinant of patient's self-perceived quality of life. Our study corroborates previous studies which showed that dyspnoea is one of the main determinants of the disease-specific HRQL and has moderate-to-strong correlation with impairment in the HRQL of patients with $\mathrm{COPD}^{27,28}$.

In the symptom subscale, dyspnoea was the only significant explanatory variable independently accounting for $27 \%$ of the variance in the quality of life sub score. The classical symptoms of COPD like cough, sputum production and wheeze were not found to influence significantly on quality of life neither did functional variables like FEV1. This observation shows that breathlessness occupies an overriding influence on HRQL over other symptoms of the disease. In the activity subscale, breathlessness accounted for a greater proportion of the variance in the HRQL, representing $42 \%$ of the total variance in this subscale. This further shows that restriction in activity in COPD is primarily due to breathlessness. The variance in the impact subscale was also influenced independently by the perception of breathlessness, weight loss and dyspnoea score on the VAS post exercise. They accounted for $24 \%$ of the total variance in this subscale. The relatively low percentage in the accounted variance of the impact subscale model may be due to the fact that anxiety and depression were not measured in this study. Anxiety and depression have been shown to influence the impact score in COPD because they encompass the psychological and social dimension of the disease. It's been suggested that variables dependent on the psychological spheres exert a decisive influence on the way in which patients live with their disease and hence the HRQL ${ }^{26}$. 

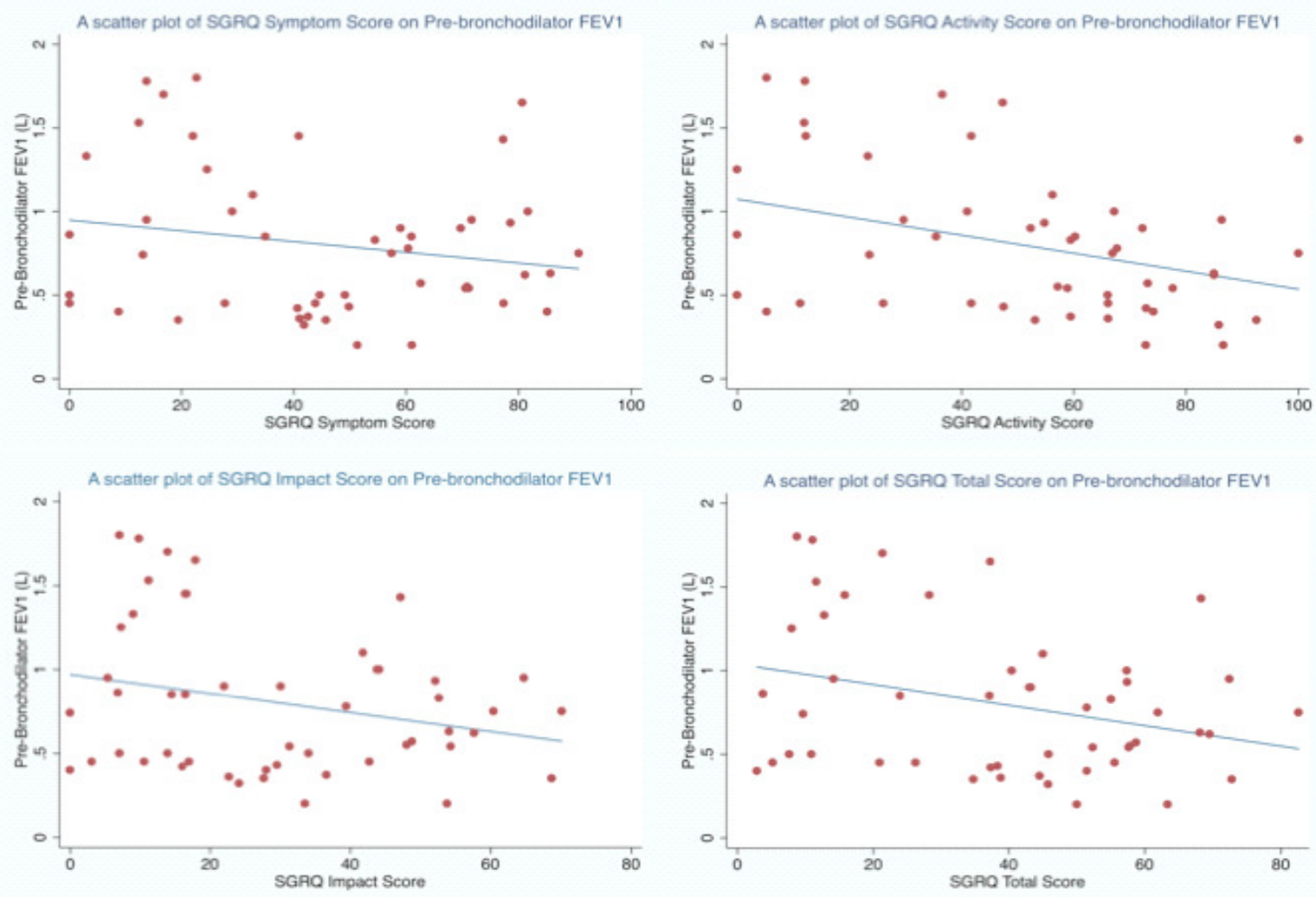

Figure 1 (a-d): Scatter plots showing the relationship of FEV1 and SGRQ component and total scores

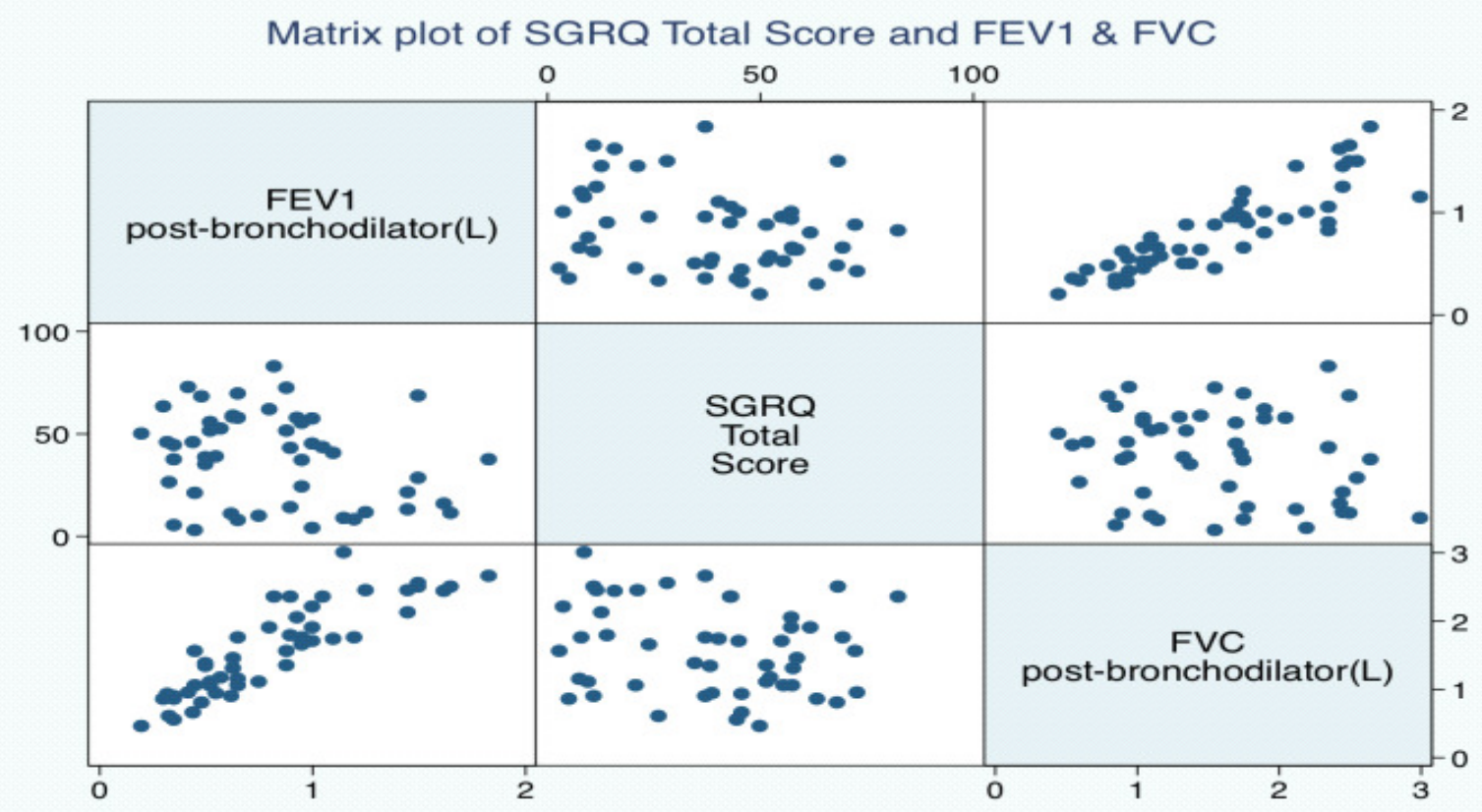

Figure 2: A matrix plots of SGRQ total score and Post bronchodilator FEV1 \& FVC. 
Lastly, the multiple regression analysis performed using the SGRQ total score showed that adjusting for age, sex, FEV1 and smoking, the model which includes self reported breathlessness and weight loss account for $35 \%$ of the variance in the SGRQ total score. Weight loss has been reported as an indicator of outcomes in numerous studies on COPD ${ }^{29,30}$. In our study, it accounted in the unadjusted model for $13 \%$ of the variance in the impact subscale and $11 \%$ of the total scores (data not shown). The aetiology of weight loss in COPD is possibly multi-factorial and factors implicated include increase workload of laboured breathing, under-nutrition due to breathlessness. The resultant effect is a reduction in muscle strength, endurance and participation in social activities and under-nourishment making COPD patients prone to recurrent infection, increase hospitalization and increased mortality from the disease $^{31}$.

This study has some limitations. It was a hospitalbased survey and as such, the participants included in the study may be skewed towards the very sick patients. Patients often do not access health care in low resource settings until their clinical condition becomes very dire because of the cost of care. This potentially limits the ability to generalise the results of this study to all COPD patients.

\section{Conclusion}

This study showed some important implications for the care of COPD in low-income settings. Spirometry remains a core investigative modality in the management of COPD however it should be complemented with measures of quality of life. In addition the presence of reported breathlessness indicates poor health status and local clinicians may use this variable as the primary indicator of a patient's self-perceived quality of life. A simple measure of breathlessness on a linear scale post exercise may also provide significant guide into the clinical state of a patient with COPD.

This study also showed that SGRQ quality scores are weakly correlated with spirometry and it's core predictors are self-reported weight loss and breathlessness.

\section{Acknowledgments}

We wish to acknowledge the support of the Obafemi Awolowo University teaching hospital in actualizing this research. We also wish to thank the house officers and resident physicians in the respiratory unit of the hospital for their kind assistance during the course of this study.

\section{References}

1. Lozano R, Naghavi M, Foreman K, Lim S, Shibuya K, Aboyans V, Abraham J, Adair T, Aggarwal R, Ahn SY. Global and regional mortality from 235 causes of death for 20 age groups in 1990 and 2010: A systematic analysis for the global burden of disease study 2010. The Lancet 2013; 380(9859):2095-128.

2. Lopez A, Shibuya K, Rao C, Mathers C, Hansell A, Held L, Schmid V, Buist S. Chronic obstructive pulmonary disease: Current burden and future projections. European Respiratory Journal 2006; 27(2):397-412.

3. Fletcher C, Peto R. The natural history of chronic airflow obstruction. BrMed J 1977; 1(6077):1645.

4. Peto R, Speizer F, Cochrane A, Moore F, Fletcher C, Tinker C, Higgins I, Gray R, Richards $\mathrm{S}$, Gilliland J. The relevance in adults of air-flow obstruction, but not of mucus hypersecretion, to mortality from chronic lung disease. results from 20 years of prospective observation. Am Rev Respir Dis 1983;128(3):491.

5. Curtis J, Patrick D. The assessment of health status among patients with COPD. European Respiratory Journal 2003;21(41 suppl):36s-45s.

6. Aghanwa HS, Erhabor GE. Specific psychiatric morbidity among patients with chronic obstructive pulmonary disease in a nigerian general hospital. J Psychosom Res 2001;50(4):17983.

7. Jones PW, Quirk F, Baveystock C. The st george's respiratory questionnaire. Respir Med 1991;85:2531.

8. Jones PW, Quirk FH, Baveystock CM, Littlejohns P. A self-complete measure of health status for chronic airflow limitation. the st. george's respiratory questionnaire. Am Rev Respir Dis 1992 Jun;145(6):1321-7.

9. Diener E, Suh E. Measuring quality of life: Economic, social, and subjective indicators. Soc Indicators Res 1997;40(1):189-216.

10. Miller TR. Variations between countries in values of statistical life. Journal of Transport Economics and Policy 2000:169-88.

11. Pauwels RA, Buist AS, Calverley PMA, Jenkins CR, Hurd SS. Global strategy for the diagnosis, management, and prevention of chronic obstructive pulmonary disease NHLBI/WHO global initiative for chronic obstructive lung 
disease (GOLD) workshop summary. American Journal of Respiratory and Critical Care Medicine 2001;163(5):1256-76.

12. Beretta L, Santaniello A, Lemos A, Masciocchi M, Scorza R. Validity of the saint george's respiratory questionnaire in the evaluation of the health-related quality of life in patients with interstitial lung disease secondary to systemic sclerosis. Rheumatology 2007;46(2):296-301.

13. Padilla A, Olveira G, Olveira C, Dorado A, Plata AJ, Gaspar I, Pérez-Frías J. Validity and reliability of the st george's respiratory questionnaire in adults with cystic fibrosis. Archivos $D e$ Bronconeumología (English Edition) 2007;43(4):20511.

14. Wilson CB, Jones PW, O'LEARY CJ, Cole PJ, Wilson R. Validation of the st. george's respiratory questionnaire in bronchiectasis. American Journal of Respiratory and Critical Care Medicine 1997;156(2):536-41.

15. Femi-Pearse D, Elebute EA. Ventilatory function in healthy adult nigerians. Clin Sci 1971 Sep;41(3):203-11.

16. Medical Section of the American Lung Association. Standardization of spirometry: 1994 update. Am Rev Respir Dis 1994;152:1107-36.

17. Crapo RO, Casaburi R, Coates A, Enright P, MacIntyre N, McKay R, Johnson D, Wanger J, Zeballos R, Bittner V. ATS statement: Guidelines for the six-minute walk test. Am J Respir Crit Care Med 2002;166(1):111-7.

18. Grant S, Aitchison T, Henderson E, Christie J, Zare S, McMurray J, Dargie H. A comparison of the reproducibility and the sensitivity to change of visual analogue scales, borg scales, and likert scales in normal subjects during submaximal exercise. Chest Journal 1999;116(5):1208-17.

19. Ferrer M, Alonso J, Prieto L, Plaza V, Monso E, Marrades R, Aguar M, Khalaf A, Antó J. Validity and reliability of the st george's respiratory questionnaire after adaptation to a different language and culture: The spanish example. European Respiratory Journal 1996;9(6):1160-6.

20. Xu W, Collet J, Shapiro S, Lin Y, Yang T, Wang C, Bourbeau J. Validation and clinical interpretation of the st georges respiratory questionnaire among COPD patients, china. The International Journal of Tuberculosis and Lung Disease 2009;13(2):181-9.

21. Jones P, Harding G, Berry P, Wiklund I, Chen W, Leidy NK. Development and first validation of the COPD assessment test. European Respiratory Journal 2009;34(3):648-54.

22. Ferrer M, Villasante C, Alonso J, Sobradillo V, Gabriel R, Vilagut G, Masa J, Viejo J, JimenezRuiz C, Miravitlles M. Interpretation of quality of life scores from the st george's respiratory questionnaire. European Respiratory Journal 2002;19(3):405-13.

23. Jones PW. St. george's respiratory questionnaire: MCID. COPD. Journal of Chronic Obstructive Pulmonary Disease 2005;2(1):75-9.

24. Jones P. Interpreting thresholds for a clinically significant change in health status in asthma and COPD. European Respiratory Journal 2002;19(3):398-404.

25. Burge PS, Calverley P, Jones PW, Spencer S, Anderson JA, Maslen T. Randomised, double blind, placebo controlled study of fluticasone propionate in patients with moderate to severe chronic obstructive pulmonary disease: The ISOLDE trial. BMJ 2000;320(7245):1297-303.

26. Jones P. Health status measurement in chronic obstructive pulmonary disease. Thorax 2001;56(11):880-7.

27. Guyatt GH, Thompson PJ, Berman LB, Sullivan MJ, Townsend M, Jones NL, Pugsley SO. How should we measure function in patients with chronic heart and lung disease? J Chronic Dis 1985;38(6):517-24.

28. Okubadejo AA, Jones PW, Wedzicha JA. Quality of life in patients with chronic obstructive pulmonary disease and severe hypoxaemia. Thorax 1996;51(1):44-7.

29. Schols A, Soeters P, Mostert R, Saris W, Wouters E. Energy balance in chronic obstructive pulmonary disease. American Journal of Respiratory and Critical Care Medicine 1991;143(6):1248-52.

30. Landbo C, Prescott E, Lange P, VESTBO J, Almdal TP. Prognostic value of nutritional status in chronic obstructive pulmonary disease. American Journal of Respiratory and Critical Care Medicine 1999;160(6):1856-61.

31. Gray-Donald K, Gibbons L, Shapiro SH, Macklem PT, Martin JG. Nutritional status and mortality in chronic obstructive pulmonary disease. American Journal of Respiratory and Critical Care Medicine 1996;153(3):961-6.

African Health Sciences Vol 13 Issue 3 September 2013 